\title{
Cenário socioambiental de uma microbacia urbana na Amazônia oriental
}

\author{
Socio-environmental scenario of an urban microbasin in the eastern Amazon \\ Escenario socioambiental de una microcuenca urbana en la Amazonía oriental
}

\author{
Marion Lucélia Rabelo de Lima \\ ORCID: https://orcid.org/0000-0003-4022-5573 \\ Universidade Federal do Oeste do Pará, Brasil \\ E-mail: marion_rabelo@hotmail.com \\ Francianne Fontenelle Campos \\ ORCID: https://orcid.org/0000-0003-0778-6643 \\ Universidade Federal do Oeste do Pará, Brasil \\ E-mail: annefontenelle@hotmail.com \\ Joseph Simões Ribeiro \\ ORCID: https://orcid.org/0000-0001-9715-816X \\ Universidade Federal do Oeste do Pará, Brasil \\ E-mail: josephribeiro_@hotmail.com \\ Ruy Bessa Lopes \\ ORCID: https://orcid.org/0000-0002-4806-8835 \\ Universidade Federal do Oeste do Pará, Brasil \\ E-mail: ruybessa@yahoo.com.br \\ Sérgio Gouvêa de Melo \\ ORCID: https://orcid.org/0000-0002-6946-6672 \\ Universidade Federal do Oeste do Pará, Brasil \\ E-mail: sergio.melo@ulbra.br \\ Mauro Alexandre Paula de Sousa \\ ORCID: https://orcid.org/0000-0002-5798-8553 \\ Universidade Federal do Oeste do Pará, Brasil \\ E-mail: mauro.sousa@ufopa.edu.br \\ Maxwell Barbosa de Santana \\ ORCID: https://orcid.org/0000-0001-7725-0970 \\ Universidade Federal do Oeste do Pará, Brasil \\ E-mail: barbosadesantana@gmail.com \\ Lucinewton Silva de Moura \\ ORCID: https://orcid.org/0000-0002-9266-946X \\ Universidade Federal do Oeste do Pará, Brasil \\ E-mail: lucinewton.moura@yahoo.com.br
}

\begin{abstract}
Resumo
Impactos ambientais negativos de ecossistemas sensíveis, são constantemente encontradas nos mananciais em área urbana, principalmente pela ação antrópica alterando significativamente a suas características naturais. Características de fauna e flora são perdidas por consequências da ocupação desordenada causando modificação climática local. A cidade de Santarém-PA, Brasil, teve um significativo aumento populacional nas proximidades de mananciais ocasionando a modificação do ecossistema da microbacia do Urumarí, com maior intensidade a partir de 1980. O principal objetivo deste trabalho foi servir de base e orientação para futuros diagnósticos na busca de recuperação de manancial e das nascentes e do corpo receptor por toda sua extensão. Neste sentido, foi necessário a elaboração de um estudo através de um diagnóstico da real situação deste manancial, para avaliar as consequências decorrentes da ocupação desordenada e da prática inadequada dos serviços de saneamento básico prestado a comunidade deste corpo hídrico. Para isso foram delimitados e caracterizados três (3) trechos, sendo eles o mais conservado, o intermediário e o com urbanização desordenada consolidada onde em todos foram encontrados danos ambientais. A caracterização foi realizada in loco em períodos sazonais no ano de 2017 a 2019. É visível e notória a modificação do ecossistema resultado da falta de fiscalização dos órgãos competentes. O Plano Diretor Municipal precisa conter diretrizes com orientação sobre conservação e estipular limites para mananciais em trechos urbanos além de estar associado a um forte acervo de medidas reguladores e de controle que facilitem a fiscalização e o monitoramento por parte do poder público constituído.
\end{abstract}

Palavras-chave: Dano ambiental; Ocupação desordenada; Poluição de ambientes aquáticos; Recuperação de manancial. 


\begin{abstract}
Negative environmental impacts of sensitive ecosystems are constantly found in urban areas, mainly due to anthropic action that significantly alters their natural characteristics. Characteristics of fauna and flora are lost due to disorderly occupation, causing local climate change. The city of Santarém-PA, Brazil, had a significant population increase around the water sources causing a change in the ecosystem of the Urumarí watershed, with greater intensity from 1980 onwards. Of the Urumarí microbasin. In this sense, it was necessary to carry out a study to assess the consequences of disorderly occupation and the lack of basic sanitation services provided to the community around the water body. For this purpose, three (3) sections were delimited and characterized, being the most conserved, the intermediate and the one with consolidated disorderly urbanization, where negative environmental impacts were found in all of them. The characterization was carried out in loco in seasonal periods from 2017 to 2019 . The ecosystem's modification is visible and notorious, culminating in the lack of inspection by the competent bodies. The Municipal Master Plan must contain guidelines with guidelines on conservation and stipulate limits for water sources in urban stretches, in addition to being associated with a strong set of regulatory and control measures that facilitate inspection and monitoring by the constituted government, as they are only protected by the Brazilian Forest Code.

Keywords: Environmental damage; Disorderly occupation; Pollution of aquatic environments; Environmental recovery.

\section{Resumen}

Los impactos ambientales negativos de los ecosistemas sensibles se encuentran constantemente en las áreas urbanas, principalmente debido a la acción antrópica que altera significativamente sus características naturales. Las características de la fauna y la flora se pierden debido a la ocupación desordenada, provocando el cambio climático local. La ciudad de Santarém-PA, Brasil, tuvo un aumento poblacional significativo alrededor de las fuentes de agua provocando un cambio en el ecosistema de la cuenca del Urumarí, con mayor intensidad a partir de 1980 en adelante. De la microcuenca Urumarí. En este sentido, fue necesario realizar un estudio para evaluar las consecuencias de la ocupación desordenada y la falta de servicios básicos de saneamiento brindados a la comunidad alrededor del cuerpo de agua. Para ello se delimitaron y caracterizaron tres (3) tramos, siendo el más conservado, el intermedio y el de urbanización desordenada consolidada, donde se encontraron impactos ambientales negativos en todos ellos. La caracterización se realizó in loco en períodos estacionales de 2017 a 2019. La modificación del ecosistema es visible y notoria, culminando en la falta de fiscalización por parte de los órganos competentes. El Plan Maestro Municipal debe contener lineamientos con lineamientos de conservación y estipular límites para las fuentes de agua en tramos urbanos, además de estar asociado a un conjunto fuerte de medidas regulatorias y de control que faciliten la inspección y seguimiento por parte del gobierno constituido, ya que solo están protegidas. por el Código Forestal Brasileño.
\end{abstract}

Palabras clave: Daño ambiental; Ocupación desordenada; Contaminación de ambientes acuáticos; Recuperación ambiental.

\title{
1. Introdução
}

As relações entre as políticas urbanas e ambientais representam um grande desafio para a formulação das respostas às pressões urbanas versus conservação ambiental (Alvim, 2014). De acordo com Tucci (2008) e Pereira et al. (2010), os impactos ambientais sobre águas urbanas, decorrem possivelmente do uso e ocupação inadequados do solo provocando poluição difusa e aumento expressivo da carga de sedimentos para corpos receptores. Entre outros passivos ambientais negativos que vulnerabilizam a resiliência e a autodepuração das águas urbanas estão: aumento das cargas orgânicas, alterações na qualidade físico-química da água, perda de vazão, redução da riqueza biológica entre outros (Sperling, 2017).

O município de Santarém, localizado na Região Oeste do Estado do Pará, Brasil, possui áreas urbanas e suburbanas no centro do município densamente povoadas embora não conte serviço de infraestrutura adequados a demanda de crescimento urbano atual da região. Indicadores colhidos pelo Censo demográfico de 2010 (IBGE, 2011) revelam uma taxa de pobreza entre a população de 54,88\% e um índice de desenvolvimento humano (IDH) de 0,75 considerado médio, mas abaixo do IDH médio brasileiro.

Devido a esse processo acelerado de urbanização (Almeida et al., 2020), os mananciais da região, se transformaram em um grande problema de ordem social e ambiental nos últimos anos, sofrendo alterações nas paisagens, alterando a benignidade ambiental das águas urbanas e suburbanas, não restaurando assim os serviços ambientais oferecidos as populações humanas. 
Esse cenário, possivelmente está associado a uma significativa taxa de urbanização, cerca de $73 \%$, e a falta de cobertura dos serviços de esgoto além de fragilidade nos demais serviços de saneamento ambiental. Apenas $0,5 \%$ de cobertura é realizada por rede coletora de esgoto, sendo o restante da cobertura distribuído entre fossas sépticas, fossas rudimentares ou negras, valas e emissão direta em corpos receptores, já a coleta de lixo é realizada em apenas 52,64\% dos domicílios. Considerando a imensa malha hídrica do município de Santarém e o longo período de chuvas na região há de acordo com Maduro (2020) alta propensão de intensos escoamentos superficiais e alagamentos. O Município de Santarém atualmente não conta com uma rede de drenagem de águas pluviais que atenda a sua taxa de urbanização.

Sem instrumentos adequados de regulação e controle fiscalizatório para o consequente monitoramento por parte do poder público, estes corpos hídricos se tornam vulneráveis as ações de uma urbanização desordenada, portanto a aplicação de políticas públicas e a inserção de instrumentos pedagógicos como a educação ambiental fazem-se necessárias e se tornam um grande avanço nas problemáticas socioambientais na gerência das coleções d'água afim de concretizar uma proposta de ambiente natural com menos vulnerabilidade causadas pela ação antrópica.

Neste contexto, é de fundamental importância abordagens sistémicas dos passivos ambientais no curso hídrico do Urumarí, enfatizando a necessidade da construção de um modelo de desenvolvimento que harmonize a melhoria da qualidade de vida da população que vive no entorno da microbacia.

O estudo teve como objetivo desenvolver uma abordagem visual exploratória sobre uma microbacia urbana na Amazônia oriental brasileira e seus passivos socioambientais, tais como: integridade da zona ripária, presença de assoreamento e erosão ao longo da microbacia, rede de drenagem pluvial, acesso a água e serviços de esgotamento sanitário.

\section{Material e Métodos}

\subsection{Localização da área de estudo}

A área de estudo está localizada no município de Santarém estado do Pará, mesorregião do baixo amazonas, situado à margem direita do Rio Tapajós na confluência com o Rio Amazonas, (IBGE, 1990; SEMMA/CIAM, 2013) e encontra-se entre as coordenadas de Longitude $-54^{\circ} 43^{\prime} 30,00^{\prime \prime}$ e $-54^{\circ} 40^{\prime} 35,00^{\prime \prime}$ Oeste e Latitude $-2^{\circ} 25^{\prime} 48,00^{\prime \prime},-2^{\circ} 30^{\prime} 46,00^{\prime \prime}$ Sul. A delimitação topográfica da microbacia do Urumarí (Figura 1) abrange aproximadamente 7,5 km e possuem suas nascentes principais na vizinhança de uma unidade de conservação municipal (área de proteção ambiental Saubal) e desagua na confluência dos rios Amazonas e Tapajós.

O curso da microbacia percorre quatorze bairros da zona urbana do município de Santarém que são respectivamente: Vigia, Área Verde, Santo André, Urumarí, Ipanema, Uruará, Diamantino, Jutaí, São José Operário, Livramento, Pérola do Maicá, Santana, Interventoria e Maicá. O estudo foi conduzido durante o "inverno" Amazônico (dezembro a junho), que é marcado por fortes chuvas, este inverno causa grandes transtornos, o que segundo Pimentel (2021) acaba prejudicando a mobilidade nesta região que há mais de cinco décadas após o início de sua expansão, ainda cresce de forma desordenada em direção ao corpo hídrico. Ocorre Santarém, uma precipitação pluviométrica anual em torno de $2.000 \mathrm{~mm}$, com distribuição irregular, mostrando a ocorrência de dois períodos nítidos de chuvas, com o mais chuvoso abrangendo o período de dezembro a junho, concentrando mais de $70 \%$ da precipitação anual (Embrapa, 2001). 
Figura 1. Mapa de localização da área de estudo em relação ao município de Santarém e delimitação da drenagem da microbacia.

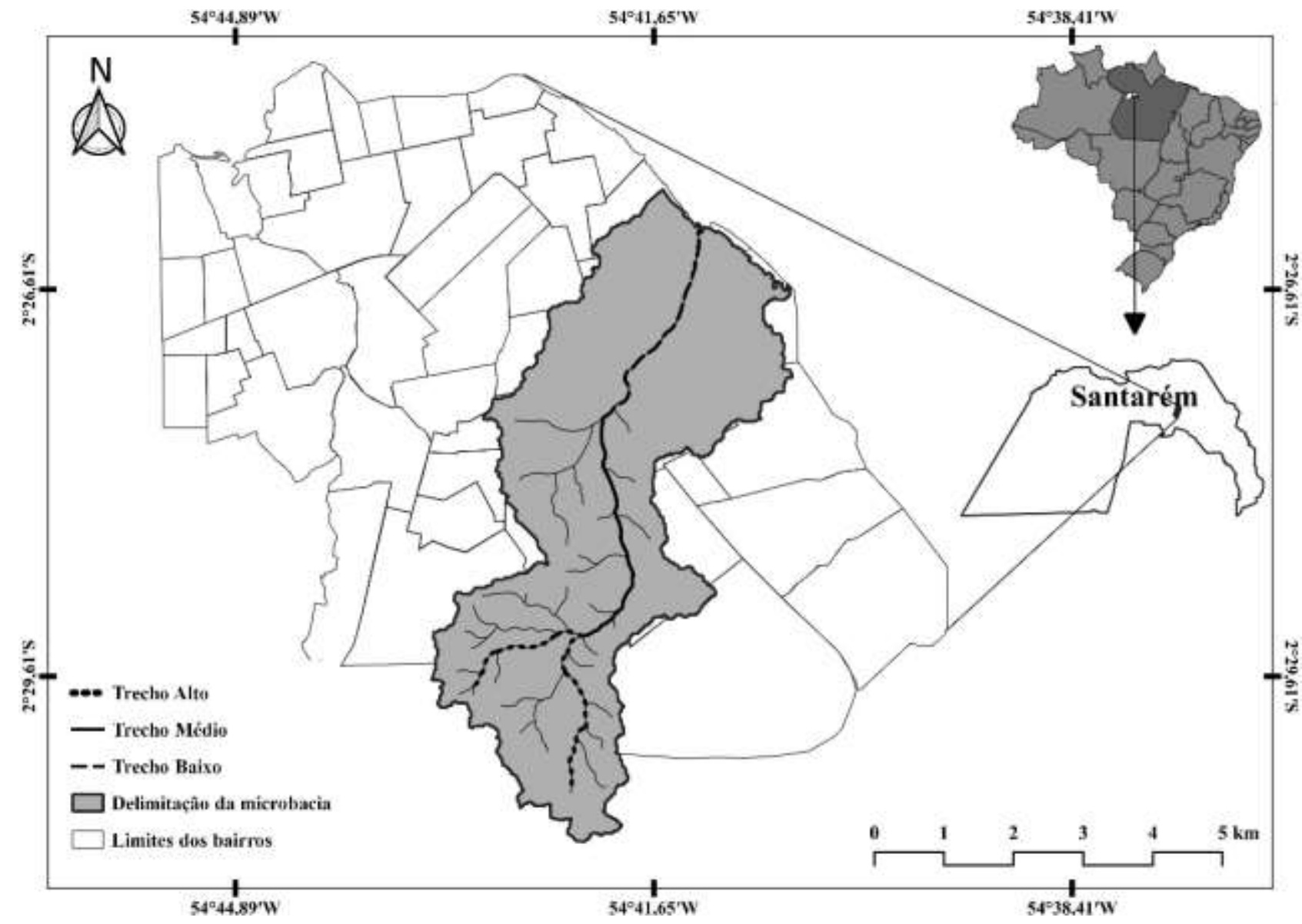

Fonte: Autores.

\subsection{Desenho do estudo}

O estudo foi de natureza quali-qualitativa descritiva, construído em dois vértices, sendo estes, avaliação das evidências ambientais observadas em campo, em associação a um questionário semiestruturado e valeu-se também do auxílio de técnicas de geoprocessamento como análises temporais, composições coloridas, classificação de uso e ocupação do solo com o uso de imagens do satélite Sentinel 2 e de altimetria e delimitação de bacias através de imagens do Satélite ALOS Palsar- 2 para obter um delineamento de cenário socioambiental rápido do locus do estudo.

As avaliações de campo ocorreram nos meses de setembro de 2017 a março de 2019. Para fins de ordenação das amostras dividiu-se a microbacia em três trechos, 1: Alto (nascente e proximidades); 2: Médio (trecho intermediária do curso da microbacia do Urumarí e 3: Baixo (trecho da foz da microbacia do Urumarí e proximidades). A avaliação da microbacia foi estruturada de forma visual como preconiza Vergara (2009) associada a aplicação de questionário.

O questionário foi estruturado em blocos que continham questões sobre acesso a água, acesso a coleta e tratamento de esgoto, gestão de resíduos sólidos e drenagem. O mesmo foi aplicado em domicílios do locus de estudo (sete bairros). A microbacia foi então dividida em três (3) trechos a saber: trecho alto, compreendido no estudo pelo bairro Vigia; Trecho médio compreendeu os bairros Santo André, Urumarí e Jutaí e finalmente o trecho baixo, composto pelos bairros, São José Operário, Área Verde, e Uruará (Figura 2). Essa escolha por estes bairros da microbacia se deu pela relativa facilidade de acesso aos mesmos. 
Figura 2. Imagem em composição colorida do satélite Sentinel 2, obtida no dia 12 de novembro de 2019, demonstrando os bairros que ocorreram a aplicação dos questionários.

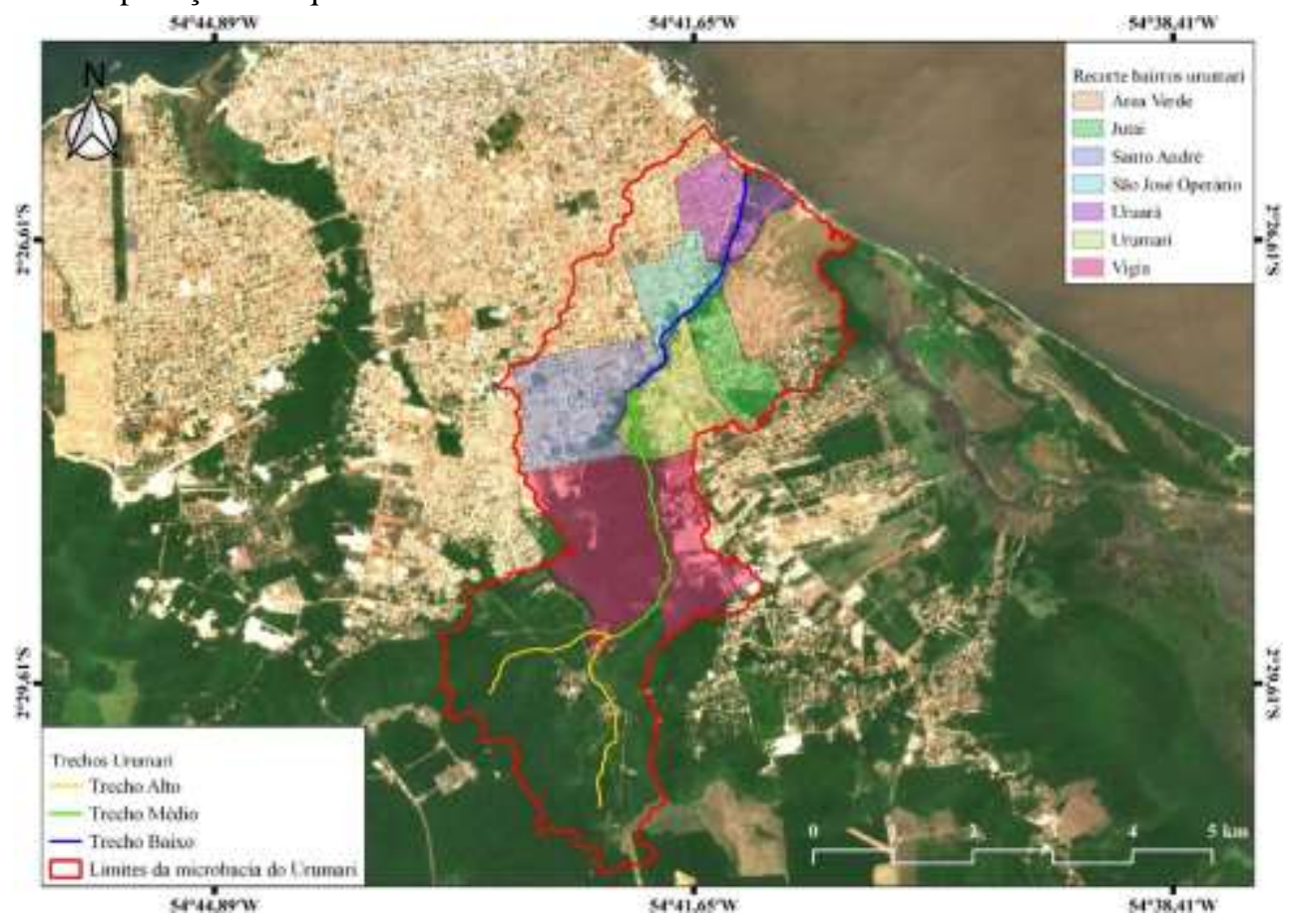

Fonte: Autores.

O questionário foi aplicado mediante o consentimento dos voluntários junto a um termo de livre consentimento elaborado e apresentado a cada um dos voluntários deste estudo.

A população investigada foi de 6.250 domicílios correspondentes aos sete (7) bairros eleitos para o estudo, a partir de um intervalo de confiança de quatro (4) e um nível de significância de 95\%. A amostra calculada foi então de 5,79\% da população de domicílios, correspondendo então a uma amostra total de 362 domicílios.

Em seguida procedeu-se ao sorteio de uma subamostra por meio da escolha de 100 domicílios através de uma randomização aleatória simples, tal subamostra correspondeu então a alíquota de domicílios observados neste estudo. Para tanto utilizou-se mapa da área urbana de Santarém com a respectiva localização dos domicílios existentes.

\section{Resultados e Discussão}

\subsection{Trecho alto}

Constatou-se visualmente neste trecho de nascente a captação irregular de água por domicílios próximos, causando desmatamento nas proximidades do corpo d'agua e erodibilidade das margens. A longo deste trecho, observou-se nitidamente o alargamento do trecho transversal da calha, provavelmente, para facilitar a balneabilidade, alterando significativamente a velocidade do curso d'agua da microbacia. Esta nova condição ambiental trouxe possíveis danos ambientais importantes como redução dos níveis de aeração da água com consequente diminuição dos gradientes de oxigênio dissolvido como citado por Sperling (2017), muito embora a taxa fotossintética possivelmente possa ter sido incrementada temporariamente.

A ocupação de margens de cursos de água ocorre há mais de 50 anos de forma desordenada não respeitando as áreas de preservação permanente (APP's no Município de Santarém. Resulta na alteração da mata ciliar e causa sérios danos ambientais, como o assoreamento, deposição direta de efluentes domésticos e lixo, e a eliminação total ou parcial da fauna aquática e terrestre no habitat (Lima et al., 2012; Oliveira Junior et al., 2021). Na Figura 3 observa-se o trecho alto da microbacia e seu uso e ocupação do solo do local. Esse trecho é representado apenas pelo bairro Vigia que apresentou cerca de 
91,36\% de sua área do trecho alto da microbacia sendo composta de área vegetada, sendo distribuída em 73,11\% de vegetação secundária densa e 18,25\% de vegetação rasteira. Apenas $8,63 \%$ da área deste bairro é edificada.

Esse bairro tem apresentado tendência de crescimento na impermeabilização do solo nos últimos anos, principalmente devido a pavimentação pelo da expansão urbana que ocorre na localidade, dado o fato de sua localização ser próxima a um dos bairros mais populosos do município de Santarém, que é o bairro Nova república, o que acaba tornando o bairro Vigia um dos principais alvos da expansão mais intensa nas áreas mais preservadas da microbacia. Essa expansão já causa efeitos na qualidade da água do trecho observado como apresentado em trabalhos de Moura et al. (2020) e Sousa et al. (2021).

Figura 3. imagem composição colorida do satélite Sentinel 2 e mapa de uso e cobertura do solo nos limites da microbacia do Urumarí, obtida no dia 18 de novembro de 2018.
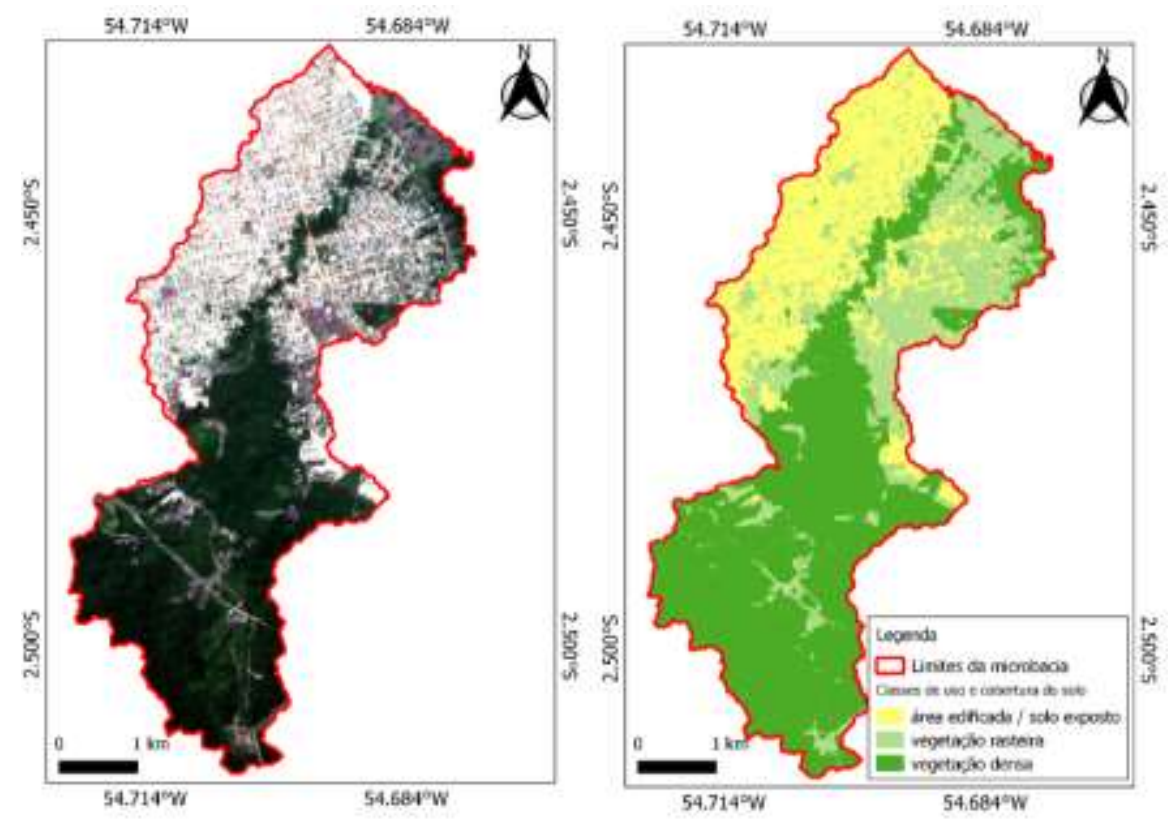

Fonte. Sousa et al. (2021).

Nesse trecho houve dominância da vegetação secundária evidenciada por espécies pioneiras regeneradoras de florestas como ingá (Inga spp), lacre (Vismia guianensis), cássia (Senna sp) e embaúba (Cecropia spp). Apenas em poucos locais foram encontradas franjas de vegetação primaria como miriti (Mauritia flexuosa) típica da mata ripária de riachos amazônicos (Santos et al., 2016).

Também observou-se, fitofisionomia modificada pela introdução de espécies como castanha do Pará (Bertholletia excelsa), cumaru (Dipteryx odorata) e frutíferas de grande e pequeno porte como o cupuaçu (Theobroma grandiflorum) de buritizeiros (Mauritia flexuosa) também observados por Pimentel et al. (2014; 2021). Muito embora haja diversidade de espécies botânicas no trecho alto da microbacia, estas indicam a remoção da mata ripária original, que segundo Martins (2007) a preservação das matas ciliares acarretam um menor carreamento de solo para o rio, menor erodibilidade e, portanto, maior regulação hídrica, evitando assim o transbordamento da calha e enchentes.

\subsection{Trecho médio}

Ao longo do trecho médio se encontrou diversas pequenas nascentes em áreas particulares, com leito protegido destinadas a diferentes atividades econômicas. Assim como no trecho alto, mais conservado,, também há presença constante de espécimes alóctones como bambuzais e em diversas propriedades, próximas ao curso d’água, a supressão da mata ripária 
(Pimentel et al., 2021). A zona de mata ripária, neste trecho está ocupada por domicílios irregulares quanto a situação fundiária e conta com serviços de saneamento básico precários, como acesso a água, coleta de lixo, esgotamento sanitário e drenagem.

A intersecção do trecho alto com o médio possui alto índice vegetativo devido a baixo ocupação humana, por apresentar elevação entre 80 a 150 metros e terreno acidentado, de difícil acesso para construção habitacional (Figura 4). Após esse trecho, o terreno apresenta menor declividade e terrenos menos acidentados e ondulados, facilitando a construção de habitações reduzindo assim a área florestada até o trecho baixo da microbacia. Para Silva (2020), a morfologia e declividade do solo é o fator determinante para a sua ocupação, uma vez que a união desses fatores podem gerar riscos como alagamentos e deslizamentos. Fatores esses que são observados, como o maior escoamento superficial, aumento do regime de fluxo com amplas e rápidas variações de descarga que frequentemente resultam em desmoronamento e erosão das margens causando o assoreamento do corpo hídrico (Olivera \& DeFee, 2007; Shuker et al., 2012).

Figura 4. Mapa de relevo da microbacia hidrográfica do Igarapé do Urumarí com imagens do Satélite ALOS Palsar- 2, trazendo classes de declividade conforme classificação da EMBRAPA.

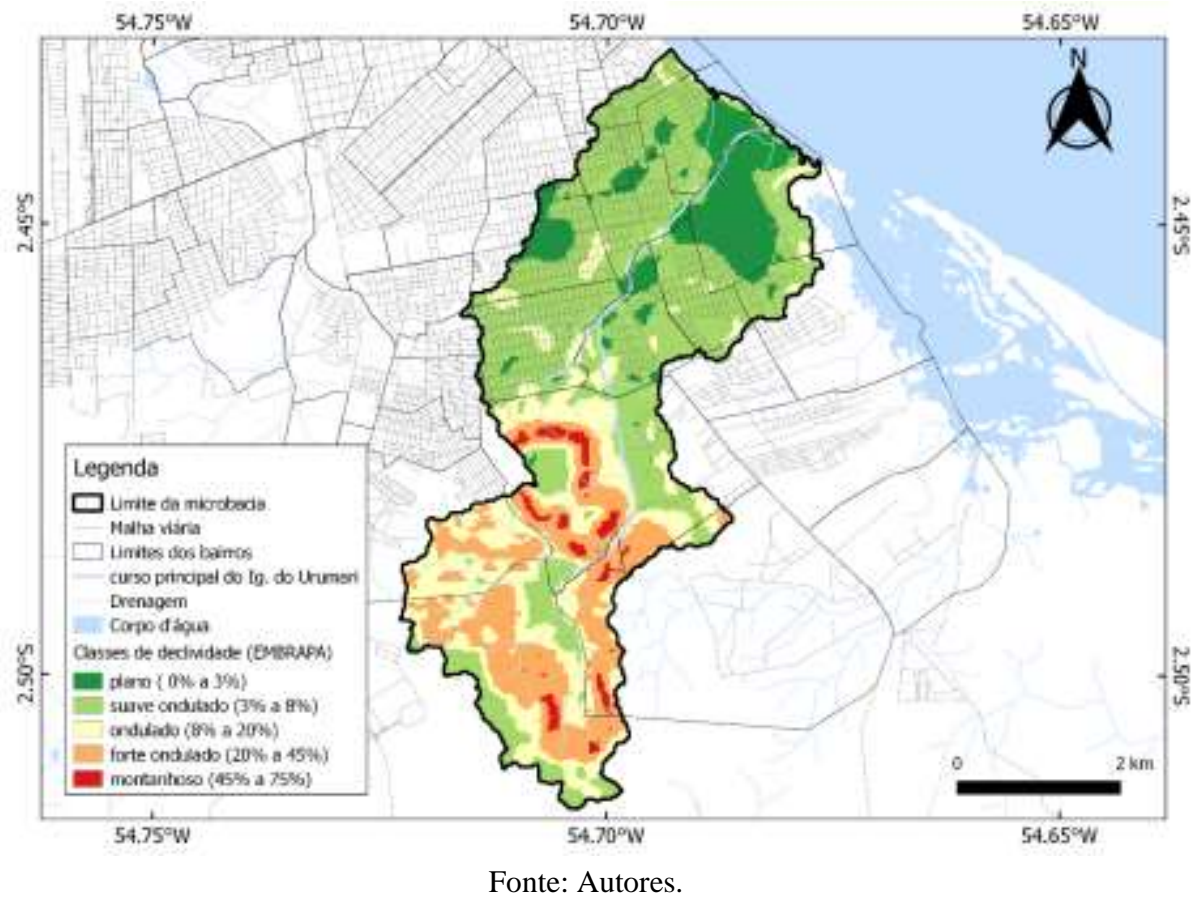

Pimentel e Melo (2014) nos apontam que até o final da década de 1970, em virtude da localização das microbacias do Urumarí, a leste e Irurá, a oeste, a expansão urbana de Santarém dava-se apenas no sentido sul da cidade e que a partir da década de 1980, a expansão avança e ultrapassa os cursos d’água que serviam de obstáculo, como pode ser observado na Figura 5 essa condição se configura no Plano Diretor do Município de Santarém (2017). A expansão urbana e de periferização de Santarém é de cerca de 73\% (IBGE, 2010) o que rebate em um êxodo rural em direção as área urbanas e periurbanas do município. Santarém ocupa atualmente, a 120a posição no ranking do Estado do Pará em população rural residente. O êxodo é entre outros fatores também decorrente da alta carência de serviços públicos e de uma taxa de pobreza que envolve $78 \%$ (IBGE, 2010) da população rural do município.

Portanto, a falta de planejamento torna vulnerável a crescente população urbana que se acomoda historicamente em áreas susceptíveis a riscos ambientais como encostas e zonas ribeirinhas além de pressionarem imobiliariamente unidades de conservação, haja vista o crescente número de conflitos ocasionados por ocupações e invasões urbanas, com especial ocorrência nos bairros periféricos (Pinho et al., 2021; Pires et al., 2018; Pinho et al.,2019); Portanto, O ritmo da expansão 
urbana no município de Santarém é dinâmico e avança rapidamente para próximo de pequenos corpos hídricos classificados como APP's, conflitos esses urbano-fundiários comuns na Amazônia atual, como citam Souza Filho et al. (2020) e Albuquerque e Molinari (2020).

Figura 5. Processo temporal de urbanização ao longo da microbacia do Urumarí de 1987 a 2018.

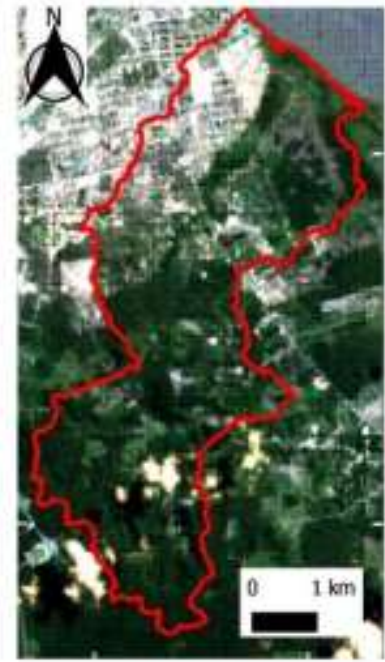

$16 / 07 / 1987$

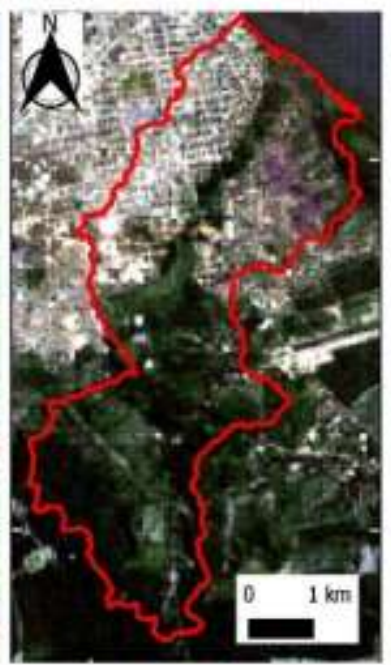

02/08/1999

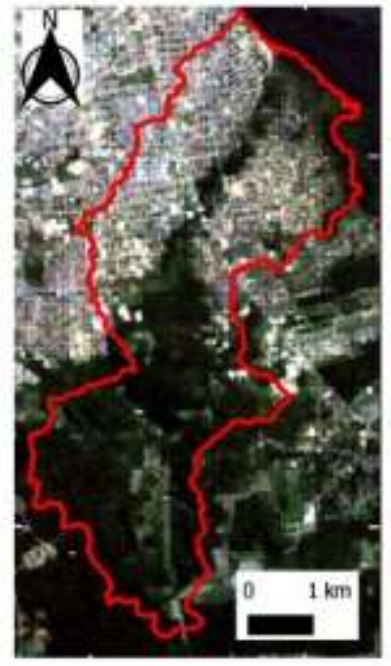

$12 / 07 / 2009$

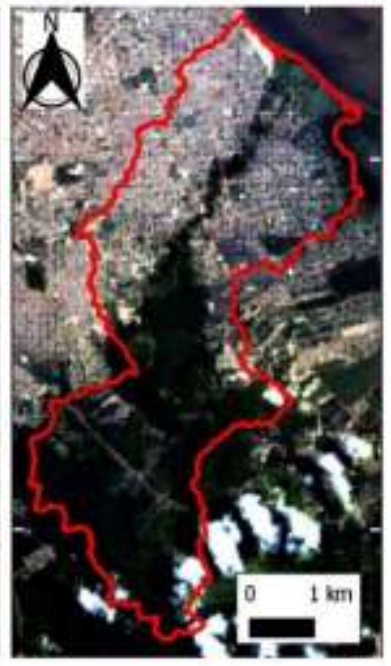

23/09/2018

Fonte. Sousa et al (2021).

Na Tabela 1 observa-se redução na área de vegetação secundária em relação ao primeiro trecho da microbacia, e maior área edificada, como um aumento de 22,94\% em relação ao bairro Vigia. Por outro lado, o bairro Santo André é responsável por 47,45\% dessa impermeabilização no solo por estar mais próximo de bairros mais populosos como Nova república, e Diamantino. Nesse Trecho da microbacia ainda se encontra com 68,43\% de área vegetada distribuída em $24,59 \%$ de vegetação densa e 43,84\% de vegetação rasteira, esta última podendo ser caracterizada em sua maioria por vegetação secundária relativa aos processos de derrubada da mata ciliar e inserção de espécies exóticas pelos moradores dos domicílios do entorno.

Tabela 1. Proporção das classes de cobertura na área de abrangência dos bairros para o trecho médio da microbacia.

\begin{tabular}{cccc}
\hline \multirow{2}{*}{ Bairro } & \multicolumn{3}{c}{ Classes de uso e cobertura do solo } \\
\cline { 2 - 4 } & Área edificada / solo exposto (\%) & Vegetação densa (\%) & Vegetação rasteira (\%) \\
\hline Santo André & 47,45 & 12,51 & 40,04 \\
Urumarí & 19,99 & 35,5 & 44,51 \\
Jutaí & 27,28 & 25,75 & 46,97 \\
\hline
\end{tabular}

Fonte: Autores.

\subsection{Trecho baixo}

A taxa de urbanização no município de Santarém gerou uma intensa urbanização e produziu impactos negativos ao meio físico que podem ser observados direta e indiretamente. No trecho em questão, não há presença de zona ripária, sendo o trecho de ocupação imobiliária mais intensa, como já observado na Figura 3e também podendo ser observados na Tabela 1 e 2 , onde há intensa cobertura de solo por edificações a oeste da bacia. 
Frequentemente, neste trecho há notificações de doenças de veiculação hídrica, devido a acentuada falta de saneamento como rede coletora de esgoto e água tratada. Esse é o ponto da microbacia com menor índice de cobertura vegetal 62,37\%, sendo o bairro Área Verde responsável por 81,16\% da cobertura vegetal, considerando o somatório da vegetação secundária densa e rastreira. Enquanto os bairros São José Operário e Uruará tem em média 52\% de média de composição vegetacional intacta, por outro lado $48 \%$ de suas áreas apresentam solo exposto (sem vegetação) ou pavimentado, demonstrando alto nível de ocupação humana presente nesses locais.

Tabela 2. Proporção das classes de cobertura na área de abrangência dos bairros para o trecho baixo da microbacia.

\begin{tabular}{cccc}
\hline \multirow{2}{*}{ Bairros } & \multicolumn{3}{c}{ Classes de uso e cobertura do solo } \\
\cline { 2 - 4 } & \multicolumn{1}{c}{ Área edificada / solo exposto (\%) } & Vegetação densa (\%) & Vegetação rasteira (\%) \\
\hline Área Verde & 18,84 & 34,21 & 46,95 \\
São José Operário & 48,51 & 18,9 & 32,59 \\
Uruará & 45,54 & 16,88 & 37,58 \\
\hline
\end{tabular}

Fonte: Autores.

Muitas dessas áreas após décadas de ocupação urbana ainda continuam sem a devida inclusão dos serviços de infraestrutura e saneamento básico, acarretando problemas previsíveis, como alagamentos de ruas e domicílios, assim como interferindo negativamente nas atividades rotineiras comerciais, institucionais e educacionais nas áreas afetadas (Melo et al., 2020).

A remoção da zona riparia ao longo da microbacia provocou assoreamento em todos os pontos visitados, inclusive na nascente da microbacia urbana do Urumarí. Para Silva (2020), o processo de assoreamento em corpos hídricos está intimamente relacionado aos processos erosivos, pois, estes são fornecedores de materiais que vão dar a origem ao assoreamento, sendo que quando não existe energia para conduzir o material erodido este é depositado as margens do manancial, bem como dito por Melo et al. (2020), em trabalho na mesma microbacia do Urumarí.

Os sistemas de drenagem urbana observados na microbacia do Urumarí são compatíveis com sistemas preventivos de inundações; formação de poças; erosões, ravinas e assoreamentos, principalmente, nas regiões mais baixas das comunidades, sujeitas a alagamentos ou marginais a cursos naturais de água, condições estas previsíveis em áreas de fundo de bacias hidrográficas. No campo da drenagem urbana, os problemas agravam-se em função da urbanização desordenada e falta de políticas públicas para o desenvolvimento urbano muito embora caiba ao poder público implantar ações que contribuam efetivamente para o transporte e escoamento das águas pluviais, evitando a poluição difusa, de modo que, o escoamento não perturbe as vias públicas e principalmente o corpo hídrico.

\subsection{0 inquérito}

As entrevistas aplicadas durante a condução do estudo revelaram que $99 \%$ dos residentes em domicílios na região da microbacia do Urumarí relatam a carência de serviços básicos de saneamento ambiental como ausência de uma rede de drenagem. Outro aspecto do estudo, revelou que entre os bairros mais afetados por inundações causado pela poluição difusa devido à falta de serviços de saneamento ambiental, são Área verde $60 \%$ e Jutaí 28,57\%. Os demais bairros, objetos também deste estudo, demonstraram a ocorrência de inundações, porém, com menor incidência. A Tabela 3 mostra a porcentagem de inundações por bairros na área da microbacia. 
Tabela 3. Bairros que sofrem influência direta da microbacia em que o entrevistado afirmou que já houve alagamento.

\begin{tabular}{ccc}
\hline \multirow{2}{*}{ Bairro } & \multicolumn{2}{c}{ Houve alagamento? } \\
\cline { 2 - 3 } & Sim $\mathbf{( \% )}$ & Não $(\boldsymbol{\%})$ \\
\hline Área Verde & 60 & 40 \\
Jutaí & 28,57 & 71,43 \\
Santo André & 13,33 & 86,67 \\
São José Operário & 516,67 & 83,33 \\
Uruará & 60 & 40 \\
Urumarí & 9,09 & 90,91 \\
Vigia & 20 & 80 \\
\hline Total de entrevistados & $\mathbf{2 6}$ & $\mathbf{7 4}$ \\
\hline
\end{tabular}

Fonte. Sousa et al. (2021).

Segundo Arcos e Santos (2012) e Lima et al. (2020) o uso e ocupação do solo tem influência direta na qualidade ambiental, estes autores apontam que locais mais florestados apresentam qualidade de água superior àqueles onde há pouca ou nenhuma vegetação. Os bairros Área Verde e Jutaí apresentaram maiores taxas de alagamento por possuírem poucas áreas de zona ripária, o que causa maior área de erosão e maiores índices de assoreamento como citado por Freitas et al. (2013) e Silva (2020). Estes autores lembram que a remoção da mata ciliar associada a baixa infraestrutura de drenagem e a uma altimetria abaixo dos 40 metros, facilita os processos de transbordo causando alagamentos.

Esses processos estão diretamente ligados a infraestrutura dos bairros, apresentados na Tabela 4, onde percebe que $50 \%$ da água servida destina-se a rua, em média $32 \%$ dos moradores dos bairros observados neste estudo lançam seu esgoto na rua e $66 \%$ em sumidouros. Essa realidade não está muito distante do restante do Brasil. Levantamentos pontam que quase 24 milhões de domicílios brasileiros não possuem tratamento de esgotos, aproximadamente, 41,7\% do total (Tischer, 2017).

Tabela 4. Destino da água servida em termos percentuais de entrevistados agrupados por bairro.

\begin{tabular}{cccc}
\hline \multirow{2}{*}{ Bairro } & \multicolumn{3}{c}{ Destino da água servida } \\
\cline { 2 - 4 } & Igarapé (\%) & Rua (\%) & Sumidouro (\%) \\
\hline Área Verde & 0 & 50 & 50 \\
Jutaí & 0 & 28,6 & 71,43 \\
Santo André & 0 & 26,7 & 73,33 \\
São José Operário & 8,3 & 16,7 & 75 \\
Uruará & 0 & 30 & 70 \\
Urumarí & 0 & 27,3 & 72,73 \\
Vigia & 2,9 & 45,7 & 51,43 \\
\hline
\end{tabular}

Fonte. Sousa et al (2021).

Observou-se nos bairros do Jutaí, Uruará e Área verde os menores índices de esgoto a céu aberto e a menor densidade populacional. Estes bairros encontram-se no trecho mais baixo da microbacia, e apresentam infraestrutura de saneamento que não é suficiente. Estes bairros apresentam taxas de alagamento maiores dos que os que possuem uma certa infraestrutura de saneamento. Como Crispin et al. (2020) citam estas condições de vulnerabilidade socioambiental no que tange a serviços de saneamento ambiental podem potencializar a frequência de doenças de via hídrica. 
Tabela 5. Residências que possuem logradouro com esgoto a céu aberto em termos percentuais agrupados por bairro.

\begin{tabular}{ccc}
\hline \multirow{2}{*}{ Bairro } & \multicolumn{2}{c}{ Esgoto a céu aberto na rua da residência } \\
\cline { 2 - 3 } & Sim $(\boldsymbol{\%})$ & Não $(\%)$ \\
\hline Área Verde & 10,00 & 90,00 \\
Jutaí & 0,00 & 100,00 \\
Santo André & 26,67 & 73,33 \\
São José Operário & 25,00 & 75,00 \\
Uruará & 40,00 & 60,00 \\
Urumarí & 0,00 & 100,00 \\
Vigia & 5,71 & 94,29 \\
\hline
\end{tabular}

Fonte. Sousa et al. (2021).

Segundo Pontes et al. (2017) no município de Belém-PA, Brasil, um caso muito semelhante ao que ocorre na microbacia do Urumarí foi relatado, em locais próximos a corpos d'água, onde a infraestrutura urbana mesmo quando adequada não impede os alagamento que ocorrem no período de inverno amazônico.

\section{Conclusão}

Na microbacia do Urumarí as condições ambientais nos diferentes trechos está alterada e oferece vulnerabilidades quanto a possíveis impactos negativos. O trecho de menor densidade populacional é o de menor fragilidade e o trecho mais baixo da microbacia é o trecho mais vulnerável devido ao intenso e não programado avanço urbano sobre o corpo hídrico. O inquérito aplicado comprovou a alta vulnerabilidade de risco socioambiental para as três áreas, especialmente no diz respeito a drenagem de águas pluviais e inundações devido a remoção da zona ripária ao longo do canal principal da microbacia com possíveis reflexos sobre a saúde pública.

A ausência de fiscalização por parte dos órgãos competentes favorece a inserção de obras irregulares sem os devidos estudos, sem as premissas da elaboração do projeto básico, liberações das licenças, levantamento topográfico da área de contribuição, impacto de vizinhança e estudo de impacto ambiental, os quais são necessários, para minimização, dos inúmeros problemas causados a sociedade como um todo, onde famílias que vivem às margens da pobreza em ambientes insalubres e sem qualquer acesso a infraestrutura, possam habitar de forma mais segura e com menor risco o entorno de um corpo receptor. Para tanto, este estudo traz uma breve caracterização das áreas marginais dos corpos hídricos e suas alterações, tendo em vista que o mesmos exerce um importante papel nas Zonas Sul e Leste do município de Santarém.

\section{Referências}

Albuquerque, N. R. de, \& Molinari, D. C. (2020). Caracterização da Cobertura Vegetal no Alto Curso da Bacia do Igarapé do Mindu - Manaus (AM). Revista Brasileira de Geografia Física, 13(1), 406-422.

Almeida, R. M. (2020). Impactos da drenagem superficial de águas pluviais na infraestrutura de trechos de vias de perímetro urbano do município de Santarém, Pará - Brasil. Revista Geonorte, . 11(37), 175-194

Almeida, R. M., Rego, R. B., Araújo, P. S. R. (2020). Saneamento, e saúde ambiental no entorno de área com habitaçãio social em Salvador, BA. Research, Society and Development, 9(7), 1-17.

Alvim, A. A. T. B. (2014). Das políticas ambientais e urbanas às intervenções: conflitos, desafios e possibilidades para áreas protegidas no meio urbano.

Arcos, F. O., \& Santos, W. L. dos. (2012). Processos erosivos às margens do rio acre: o caso área central do município de Rio Branco, Acre, Brasil. Revista Geonorte, 3(5), 622-633.

Crispim, D. L, Rodrigues, R.S .S, Vieira, A. S. A, Pessoa, F. C. L \& Fernandes, L. L (2020). Health indicators in Amazonian cities: case study in the State of Pará, Brazil. Research, Society and Development, 9(7), 1-17, e635973531.

EMBRAPA - Empresa Brasileira de Pesquisa Agropecuária. (2001). Caracterização dos solos da área do planalto de Santarém, município de Santarém, Estado do Pará (Rodrigues et al. (ed.). Embrapa Amazônia Oriental.

Freitas, L. F. de, Guimarães, R. F., Carvalho Junior, O. A. de, \& Gomes, R. A. T. (2013). Relacionamento entre a mudança da rede de drenagem devido à construção de estruturas urbanas e o surgimento de voçorocas no bairro do jardim botânico no Distrito Federal. Revista Brasileira de Geomorfologia, 13(4), 
419-433. https://doi.org/10.20502/rbg.v13i4.294

IBGE - Instituto Brasileiro de Geografia e Estatística- Censos demográficos e contagens populacionais. https://www.ibge.gov.br/estatisticas/sociais/populacao/9662-censo-demografico-2010.html?=\&t=o-que-e

Lima, A. C. de M., Fernandes, L. L., Lopes, D. F., Bittencourt, G. M., Vinagre, M. V. de A., \& Silva, E. M. da. (2020). Urbanização e canais urbanos: avaliação da qualidade das águas da bacia hidrográfica do Una no Município de Belém, Brasil. Research, Society and Development, 9(7), e232973866. https://doi.org/10.33448/rsd-v9i7.3866

Lima, K. D. de V., Arcos, F. O., \& Serrano, R. O. P. (2012). No Áreas de risco e ocupação urbana: o caso do bairro Raimundo Melo, Rio Branco, Acre Brasil. Revista Geonorte, 3(5), 197-206.

Martins, S. V. (2007). Recuperação de matas ciliares (2a ed.). Aprenda Fácil Editora.

Melo, S. G. de, Moura, L. S., Lopes, R. B., Santos, Z. Dos, Almeida, R. M., \& Silva, J. T. da. (2020). Qualidade da água de córregos sob influência da ocupação antrópica: o caso das águas urbanas e periurbanas de Santarém-PA. Revista Ibero-Americana de Ciências Ambientais, 11(7), 569-576. https://doi.org/10.6008/CBPC2179-6858.2020.007.0044

Moura, L. S. de, Lopes, R. B., Ribeiro, J. S., Fernandes, G. D. S. T., Almeida, R. M., \& Melo, S. G. de. (2020). Mathematical modeling in the Urumari microwatershed using Streeter-Phelps mathematical models and the enhanced Do-Bod model. Revista Ibero-Americana de Ciências Ambientais, 11(6), 332-345. https://doi.org/10.6008/CBPC2179-6858.2020.006.0027.

Oliveira Junior, E. S., Lima, T. E. de, Poquiviqui, A. da S., Tavares, C. da C., Machado, C. S. D., Carvalho, C. dos S., Carvalho, L. R. de, Miranda, P. R., \& Souza, C. A. de. (2021). Aplicação de protocolos de avaliação rápida como ferramenta robusta na qualificação ambiental em dois córregos urbanos que desaguam no rio Paraguai. RAEGA, 8(2), 199-220.

Olivera, F., \& DeFee, B. B. (2007). Urbanization and Its Effect On Runoff in the Whiteoak Bayou Watershed, Texas1. JAWRA Journal of the American Water Resources Association, 43(1), 170-182. https://doi.org/10.1111/j.1752-1688.2007.00014.x

Pereira, S. de F. P., Costa, A. de C., Cardoso, E. do S. C., Corrêa, M. do S. S., Alves, D. T. V., Miranda, R. G., \& Oliveira, G. R. F. de. (2010). Condições de potabilidade da água consumida pela população de Abaetetuba-Pará. REA - Revista de Estudos Ambientais, 12(1), 50-62.

Pimentel, D. R., \& Melo, S. (2014). Proteção ambiental no igarapé do Urumari, cidade de Santarém, Pará, Brasil. Revista EM FOCO-Fundação Esperança/IESPES, 1(22), 1-12.

Pimentel, D. R., Suemitsu, C., Mota, E. J., Alves, R. C. F., Ramos, P. C., Jesus, A. K. S. de, Silva, I. L. de S., \& Soares, A. de M. (2021). Diagnóstico ambiental da vegetação ripária e da microbacia de um riacho urbano amazônico. Revista Saúde e Meio Ambiente - RESMA, 12(3), 166-180.

Pinho, E. R. P., Reis, A. B. O. anais do Encontro Nacional da Associação Nacional de Pós-Graduação e Pesquisa em Planejamento Urbano e Regional..http://anpur.org.br/xviiienanpur/anaisadmin/capapdf.php?reqid=397

Pontes, M. L. C., Lima, A. M. M. de, Júnior, J. de A. S., \& Sadeck, C. C. de A. (2017). Dinâmica das áreas de várzea do município de Belém/PA e a influência da precipitação pluviométrica na formação de pontos alagamentos. Caderno de Geografia, 27, 285-303. https://www.redalyc.org/articulo.oa?id=333250465005

Prefeitura Municipal de Santarém. Minuta do Projeto de Lei de revisão do Plano Diretor de Santarém. 2017. 71 p.

Santos, O. dos A., Couceiro, S. R. M., Rezende, A. C. C., \& Silva, M. D. de S. (2016). Composition and richness of woody species in riparian forests in urban areas of Manaus, Amazonas, Brazil. Landscape and Urban Planning, 150, 70-78. https://doi.org/10.1016/j.landurbplan.2016.03.004.

Shuker, L., Gurnell, A. M., \& Raco, M. (2012). Some simple tools for communicating the biophysical condition of urban rivers to support decision making in relation to river restoration. Urban Ecosystems, 15(2), 389-408. https://doi.org/10.1007/s11252-011-0207-2

Silva, J. J. R., Oliveira, G. de A., Vieira, E. M., \& Freitas, A. C. V. (2020). Influência da expansão urbana aliada às características morfométricas nas ocorrências de inundações: estudo de caso no município de João Monlevade-MG. Research, Society and Development, 9(2), e136922101. https://doi.org/10.33448/rsd-v9i2.2101

Sousa, L. R., Ribeiro, J. S., Lopes, R. B., Melo, S. G. de, Sousa, M. A. P. de, \& Moura, L. S. de. (2021). A influência do uso e ocupação do solo na qualidade ambiental do igarapé do Urumarí, Santarém (PA). Brazilian Journal of Development, 7(11), 105186-105208.

Souza Filho, E. A. de, Alves, S. B. da S. M., Neves, R. K. R., Batista, I. H., Albuquerque, C. C. de, Damasceno, S. B., \& Nascimento, D. A. do. (2020). Estudo comparativo de aspectos físico-químicos entre águas da microbacia do mindu e igarapés sob influência antrópica na cidade de Manaus-AM. Brazilian Journal of Development, 6(1), 2419-2433. https://doi.org/hottps://dx.doi.org/10.34117/bjdv6n1-178

Sperling, M. Von. (2017). Introdução a qualidade das águas e ao tratamento de esgotos (M. Von Sperling (ed.); 4th ed.). Ed. UFMG.

Tischer, V. (2017). Magnitude do impacto do esgotamento sanitário no Brasil. Revista Gestão \& Sustentabilidade Ambiental, 6(3), 358. https://doi.org/10.19177/rgsa.v6e32017358-379

Tucci, C. E. M. (2008). Águas urbanas. Estudos Avançados, 22(63), 97-112. https://doi.org/10.1590/S0103-40142008000200007

Vergara, S. C. (2009). Começando a definir a metodologia. In: Vergara, S.C. (Ed.) Projetos e relatórios de pesquisa em administração. (pp 41-49) Atlas. 